\title{
Influence of oxide inclusions on the process of interparticle splicing of powder materials
}

\author{
Maxim Egorov ${ }^{1 *}$, Rimma Egorova ${ }^{1}$, and Zanna Ereveeva ${ }^{2}$ \\ ${ }^{1}$ Don State Technical University, 34400, Gagarin Square 1, Rostov-on-Don, Russia \\ ${ }^{2}$ MISiS National University of Science and Technology, 119991, Leninsky prospect, 4 Moscow, \\ Russia
}

\begin{abstract}
One of the characteristic features of the structure of the powder material is the increased content of oxide inclusions. In most works considering the influence of oxide inclusions on the fracture process, their contradictory role in the processes of crack initiation and development is noted, which consists, on the one hand, in creating concentrators of internal stresses, increasing the tendency of the material to brittle fracture and in reducing the plastic properties of the material, on the other, when oxide inclusions of appropriate dispersion and distribution in the volume of the matrix prevent the sliding of dislocations, thereby contributing to its strengthening. The positive effect of oxide inclusions on the mechanical properties of the material led to the development of the internal oxidation technology as one of the methods of precipitation hardening of materials.
\end{abstract}

\section{Introduction}

To control the splicing process in the manufacture of powder materials, it is necessary to identify the cause of the formation of oxide inclusions on the contact surfaces and develop technological methods that prevent their occurrence. With regard to the process of solidphase metal bonding, the negative influence on the formation of interatomic interaction of surface metal ions consists in the need to destroy the Me-O bond. Therefore, the technology of joining in the solid state of monolithic metals provides for mandatory preliminary preparation of the surface $[1,2,3]$ and protection of the joint to be joined at the stage of thermal action.

\section{Relevance and Analysis of the Problem Status}

\begin{abstract}
Alloying elements used in powder metallurgy are an important link in obtaining quality materials. Creation of new types of alloyed powders should have high properties when modified with additives. Today, it is an urgent task to increase the strength of metal products, accelerate sintering processes, homogenization of materials and obtain almost complete chemical homogeneity of powder materials.
\end{abstract}

\footnotetext{
* Corresponding author: aquavdonsk@mail.ru
} 


\section{Problem Statement}

In this article, the task is to consider the effect of oxide inclusions on the process of interparticle splicing of powder materials. During the formation of a powder material, a thermal deformation effect occurs in the zone of contact interaction of the surfaces to be joined, commensurate with the level of energy introduced into the contact area during pressure welding of monolithic materials. Consequently, in order to solve the problems of merging powder materials, it is necessary to additionally consider the theory of compaction of powder bodies. The relevance of the study of splicing also follows from the obvious fact that without reaching a certain level of development of this process, it is useless to apply any effects on the powder material to improve its properties.

\section{Theoretical Part}

The production of cold-pressed blanks is carried out in most cases without the use of a protective environment. The change in the nature of porosity during compaction of a metal powder is noted in $[3,4,5]$. It is a generally accepted fact that there is a stage of compaction with complete isolation of pores. The value of the total porosity corresponding to the beginning of the indicated stage of compaction depends on the method of obtaining the powder and, therefore, on its granulometric composition, shape and state of the surface and is in the range of $7-12 \%$. Since the granulometric composition has a significant effect on the formation of closed pores and their size, the studied powder of grade PZhV 3.160.26 was dispersed into three fractions (Table 1).

Table 1. Granulometric composition of powder grade PZhV 3.160.26.

\begin{tabular}{|c|c|c|c|}
\hline \multirow{2}{*}{ Indicators } & \multicolumn{3}{|c|}{ Faction number } \\
\cline { 2 - 4 } & 1 & 2 & 3 \\
\hline $\begin{array}{c}\text { General average } \\
\text { size, mm }\end{array}$ & 0,043 & 0,062 & 0,12 \\
\hline $\begin{array}{c}\text { Maximum } \\
\text { frequency }\end{array}$ & 52 & 33 & 15 \\
\hline
\end{tabular}

Each fraction of the powder is characterized by a general average size and frequency corresponding to that size.

The measurement of closed porosity was carried out by impregnating a cold-pressed sample with carbon tetrachloride, as a liquid that wetts iron well. Based on the results of weighing the impregnated cold-pressed sample in carbon tetrachloride, the volume of closed pores was determined and the value of closed porosity was calculated by the expression:

$$
\Pi_{3}=\left(m-R_{l}-V_{m} \cdot \rho_{l}\right) \cdot \rho_{o} /\left(m \cdot \rho_{l}\right),
$$

where :

$\mathrm{m}$ - mass of the sample;

$\mathrm{R}_{\mathrm{l}}$ - result of weighing the impregnated sample in carbon tetrachloride;

$\mathrm{V}_{\mathrm{m}}$ - volume of the metal matrix;

$\rho_{\mathrm{l}}$ - density of carbon tetrachloride;

$\rho_{0}$-density of the sample.

The dependence of closed porosity on total porosity is shown in Fig. 1,2. 


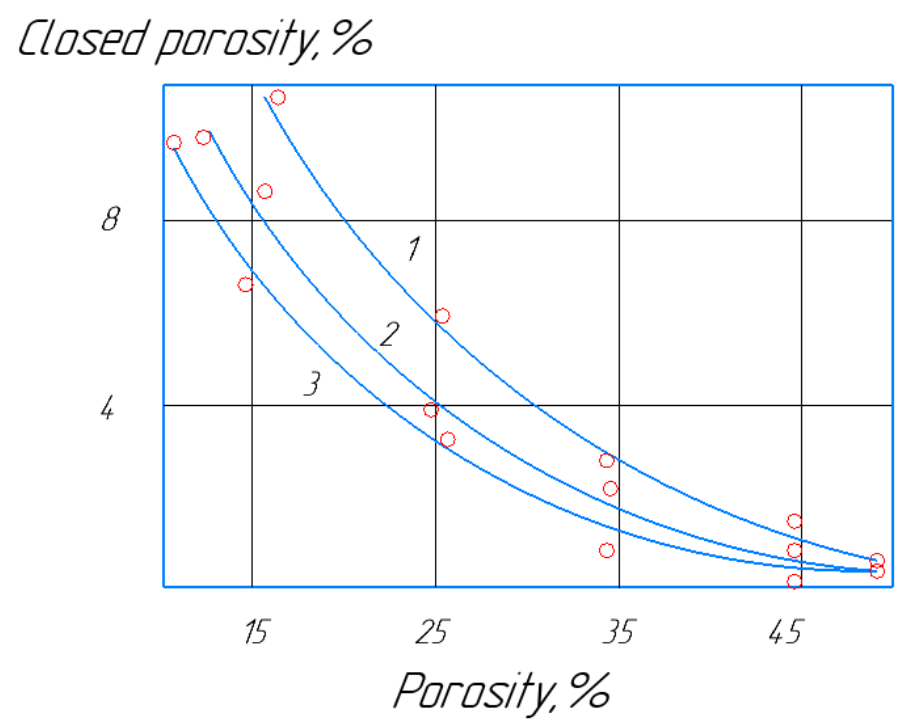

1-0,056; 2- +0,056-0,071; 3- +0,071-0,16.

Fig. 1. Dependence of the closed porosity value on the total for fractions.

With the grinding of the fraction of the pressed powder, the impermeability of the compact is achieved at a greater value of the total porosity. In addition to the total volume of closed pores, as an integral characteristic of a porous body, of interest is the pore size of compacts obtained from a powder of various particle size distribution.

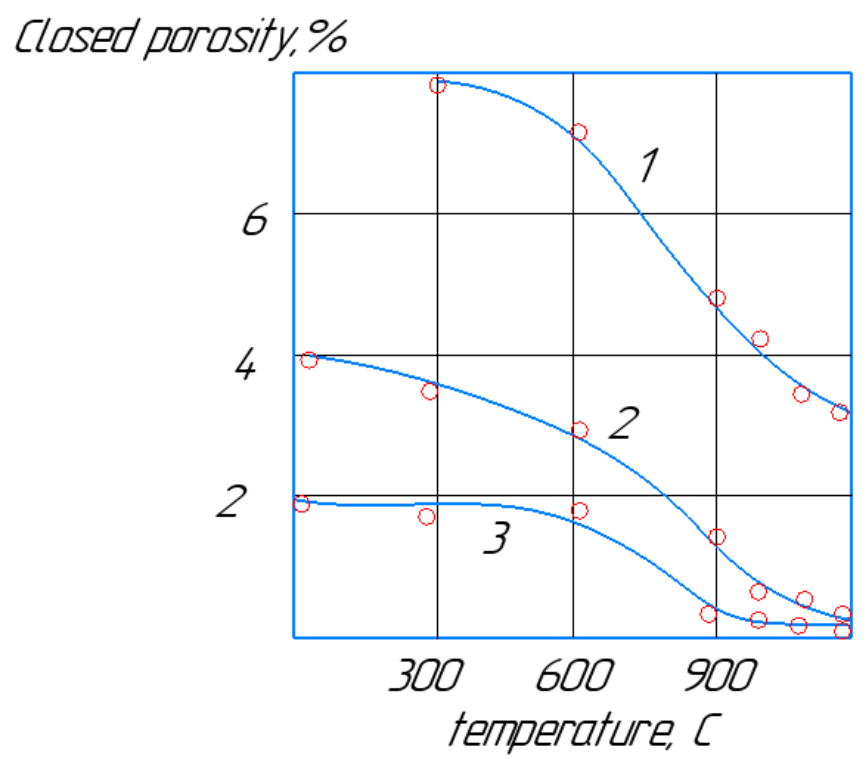

Fig. 2. Dependence of the relative volume of closed pores on the total porosity for fractions

The pore sizes were determined by microstructural analysis carried out using the developed software package. When making a thin section, the compacts were filled with epoxy resin. The measurement results are shown in table. 2. The numerator indicates the average pore size in $\mathrm{mm}$, the denominator indicates the maximum frequency in \%. 
Table 2. Average pore size

\begin{tabular}{|c|c|c|c|}
\hline \multirow{2}{*}{ Porosity,\% } & \multicolumn{3}{|c|}{ Faction number } \\
\cline { 2 - 4 } & 1 & 2 & 3 \\
\hline 12 & $0,005 / 36$ & $0,009 / 34$ & $0,013 / 36$ \\
\hline 20 & $0,008 / 33$ & $0,014 / 32$ & $0,021 / 32$ \\
\hline 30 & $0,015 / 29$ & $0,025 / 30$ & $0,041 / 31$ \\
\hline 40 & $0,025 / 31$ & $0,035 / 31$ & $0,047 / 33$ \\
\hline
\end{tabular}

Smaller pores, typical of compacts obtained from the first fraction, require a lesser degree of plastic deformation of the powder particles for their isolation, which is confirmed by the nature of the dependences shown in Fig. 1, 2.

\section{References}

[1] Yu. Dorofeev, Dynamic Hot Compaction of Porous Powder Workpieces [in Russian], Metallurgiya, Moscow (1977).

[2] Yu. Dorofeev, L. Marinenko, V. Ustimenko, Structural Power Materials and Objects [in Russian], Metallurgiya, Moscow (1986).

[3] V. Sinel'shchikov, S. Egorov, Yu. Dybov, "Study of features of failure of growth zones of heated porous material with uniaxial tension,” Progressive Technology of Engineering Systems: Proc. V Internat. Sci. Tech. Conf

[4] V. Antsiferova, Problems of Contemporary Materials and Technology [in Russian], Perm. Gos. Tekh. Univ, Perm’ (1995).

[5] M. Egorov, S.Egorov, "Hot-deformed low-alloy structural steels," RF Ministry of Education and Science, Federal Agency for Education, YuRGTU (Novocherkassk Politech. Inst.), Novocherkassk (2008). 